\title{
Blood-Aqueous Barrier Breakdown Associated with Rhegmatogenous Retinal Detachment
}

\author{
B. C. LITTLE and V. M. G. AMBROSE \\ London
}

\begin{abstract}
Summary
We compared the integrity of the blood-aqueous barrier (BAB) between normal eyes and those with first-time rhegmatogenous retinal detachment (RRD) using the technique of anterior segment fluorophotometry. We found significantly greater anterior segment fluorescence in eyes with retinal detachment $(p=<.001)$ thereby demonstrating quantitatively for the first time that there is significant damage to the BAB associated with RRD. We have also shown that the BAB permeability returns to normal within two months of successful reattachment of the retina. The origin of this transient increase in $\mathrm{BAB}$ permeability is unknown but its severity and duration may well be of significance in the pathogenesis of complications associated with RRD such as uveitis, rubeosis and proliferative vitreoretinopathy.
\end{abstract}

It is well known that anterior uveitis may be associated with rhegmatogenous retinal detachment. Anterior segment fluorophotometry (ASFP) can be used to quantify inflammation in acute anterior uveitis and has been shown to provide a more sensitive and accurate method for detecting changes in permeability than clinical observation using biomicroscopy. ${ }^{1}$ This study was undertaken in order to determine if there is a significant difference in blood-aqueous barrier (BAB) permeability between normal eyes and those with rhegmatogenous retinal detachment (RRD). Such information may contribute to the understanding of the pathogenesis of complications associated with rhegmatogenous retinal detachment, such as proliferative vitreoretinopathy (PVR) and rubeosis, where increased vascular permeability may well play a significant role.

\section{Methods}

\section{Controls}

It has been shown that there is a possible con- sensual fluorophotometric response following surgical trauma to the other eye. ${ }^{2}$ The mechanism of this is unknown and therefore the phenomenon cannot be disregarded when considering the use of fellow eyes of rhegmatogenous retinal detachments (RRDs) as controls. It was therefore considered wiser to use healthy volunteers as controls for this study in order to avoid this uncertainty. Consent was obtained after the nature of the procedure had been fully explained to the subjects.

Nine normal subjects received sodium fluorescein $20 \% \mathrm{w} / \mathrm{v} 14 \mathrm{mg} / \mathrm{kg}$ intravenously on two visits and ASFP scans were preformed on each occasion on both eyes at intervals over the subsequent 240 minutes using the Fluorotron Master (Coherent Radiation). Their mean age was 62 years (range 39-72), three males and six females, all Caucasian and all had visual acuities of at least $6 / 9$ in each eye. None was taking any systemic or eye medications or had any eye disease. Subjects were excluded if there was a positive history of severe allergy or cardiorespiratory disease.

From: St Thomas' Hospital, London SE1 7EH

Correspondence to: B. C. Little, Moorfields Eye Hospital, City Rd, London EC1V 2PD. 
Typical normal anterior segment fluorescence scans

(1) Pre-Fluorescein

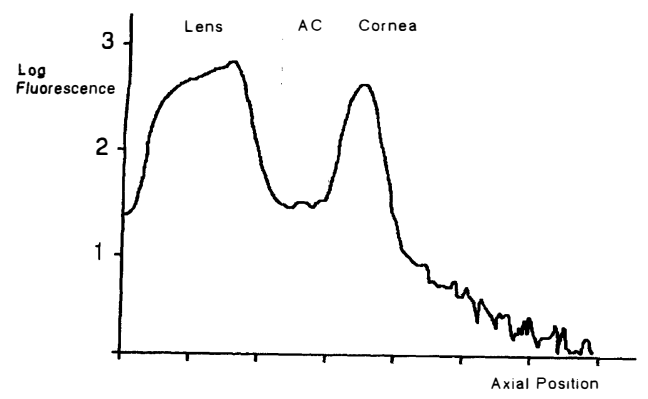

(2) Post-Fluorescein (60 min)

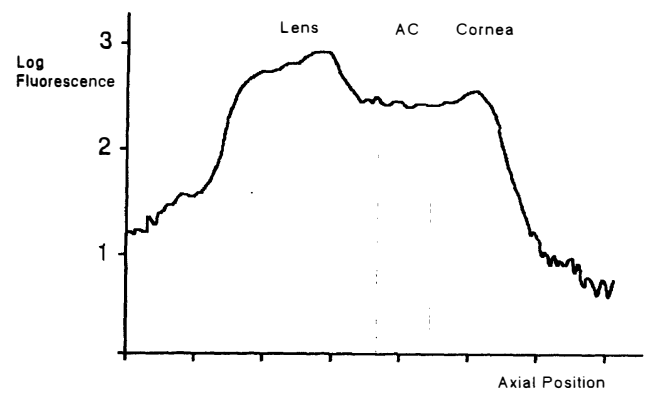

Fig. 1.

\section{Patients}

Patients chosen for this study had been admitted to hospital for repair of spontaneous, first time rhegmatogenous retinal detachment in phakic eyes. None was on either topical or systemic anti-inflammatory medications or had a history of severe allergy or cardiorespiratory disease.

Eleven patients took part (six males, five females), mean age 54 years. Ocular parameters recorded were the quadrantic extent of retinal detachment, its probable duration, the number of retinal breaks, presence of PVR and the presence and nature of any pathology in the fellow eye.

Preoperative anterior segment fluorophotometry scans were performed in both eyes of each patient approximately 10 minutes before and exactly one hour following an intravenous bolus injection of sodium fluorescein $(20 \% \mathrm{w} / \mathrm{v}) 14 \mathrm{mg} / \mathrm{kg}$. The pre-injection scan was taken to check for any abnormal fluorescence as well as to familiarise the subjects with the procedure. The post-injection scan was taken at 60 minutes because previous work shows anterior chamber (AC) levels of fluorescence plateau between 60 and 90 minutes after IV injection of fluorescein. This interval also allows for comparison of our results to be made with other studies.

Following surgery, all patients were discharged on a standard post-operative regimen of topical treatment (G. dexamethasone $0.1 \%$ qds, G. chloramphenicol $0.5 \%$ qds, G. cyclopentolate $1 \%$ bd). They were then reviewed at two months post-operatively, noting the anatomical result of the surgery and the development of any complications. Fluorophotometry scans were then repeated on the operated eye employing exactly the same protocol as used preoperatively. The interval of two months was chosen empirically as it was sufficient time to allow for resolution of the surgically induced inflammatory response.

The data from each scan were analysed using Coherent Radiation dedicated software which gave a mean value of three samples taken at the centre of the anterior chamber along the visual axis. Using the Fluorotron Master, all the results are expressed as total fluorescence in terms of equivalent concentrations of free sodium fluorescein $(\mathrm{ng} / \mathrm{ml})$ as it is impossible to distinguish between the various metabolites of fluorescein with this machine. It is accurate to within $8 \%$ or less in the range of five to $1000 \mathrm{ng} / \mathrm{ml} .^{3}$ All statistical comparisons in the patient group were made using the Student t-test.

\section{Results}

\section{Controls}

Typical normal ASFP scans both pre- and post-fluorescein are shown in Fig. 1. The results from the 36 control eyes over the 120 minutes following intravenous fluorescein $(14 \mathrm{mg} / \mathrm{kg})$ are shown in Fig. 2. Mean anterior chamber fluorescence at 60 minutes $(+/-\mathrm{SD})$ in these control eyes was $301 \mathrm{ng} / \mathrm{ml}(+/-108)$ with a range of $140-560 \mathrm{ng} / \mathrm{ml}$. Analysis of variance (nested) was used to assess the difference between right and left eyes and between first and second visits. We looked at anterior segment fluorescence in two ways:

(a) the peak level in the anterior chamber

(b) the total area under the curve 


\section{Mean AC fluorescence in 36 control eyes after IV fluorescein (14 mg/kg)}

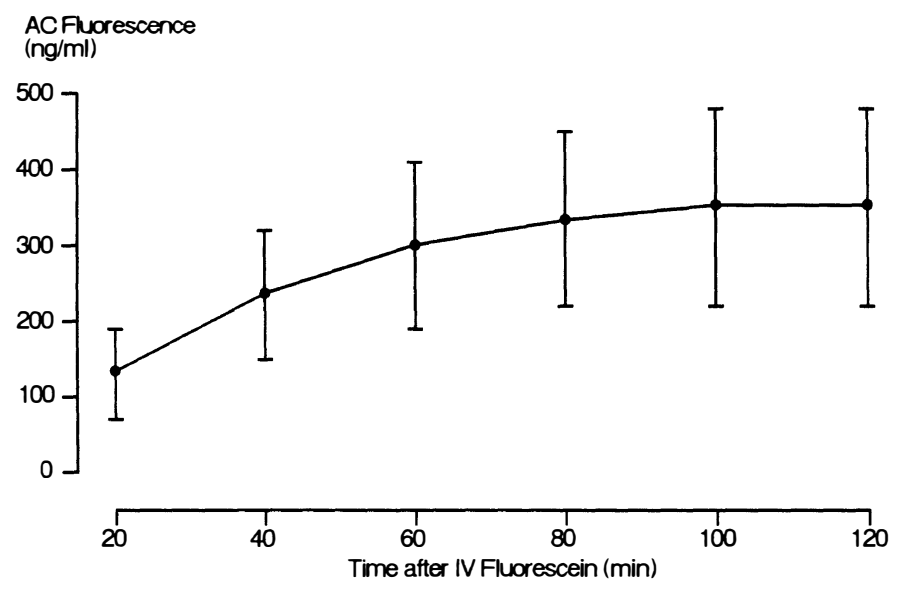

Fig. 2.

and the results are shown in Table I. Both methods gave similar results, thus emphasising the reproducibility of anterior segment fluorophotometry as a scientific technique.

\section{Patients}

All the retinas remained flat following a single surgical procedure. Statistical comparisons of anterior segment fluorescence in this group were made using the Student t-test. All parameters observed are summarised in Table II, and the basic statistics shown in Table III.

Anterior segment fluorescence of detached eyes was significantly greater than normal controls $(\mathrm{p}=<.001$, Table IV) demonstrating quantitatively for the first time that there is significant damage to the $\mathrm{BAB}$ associated with rhegmatogenous retinal detachment.

No significant difference was found between the anterior segment fluorescence of normal eyes and re-attached eyes two months post-operatively $(\mathrm{p}=.411$, Table IV). This demonstrates that $\mathrm{BAB}$ permeability returns

Table I. Correlation coefficients between anterior segment fluorescence (expressed as Peak AC value or Area under curve $(120 \mathrm{~min}))$ and right/left eyes or 1st/2nd visits.

\begin{tabular}{lcc}
\hline Correlation Coefficients & $\begin{array}{c}\text { Peak AC } \\
\text { value }\end{array}$ & $\begin{array}{c}\text { Area under } \\
\text { curve }(120 \text { min })\end{array}$ \\
\hline Right vs Left eye & 0.885 & 0.860 \\
1st vs 2nd visits & 0.871 & 0.885 \\
\hline
\end{tabular}

to normal over this interval following successful surgery and that the initial increase is presumably caused by the pathophysiological events induced by the retinal detachment.

A significant positive correlation was found between age and fluorescence in the fellow eye $(r=.77, p=.0056$, Table VI) confirming a normal variation with age observed in other studies.

No significant difference was found between the anterior segment fluorescence of detached eyes with and without PVR $(\mathrm{p}=.573$, Table V).

No significant correlation was found between fluorescence and the duration of the detachment $(\mathrm{r}=.13, \mathrm{p}=.7069$, Table VI).

No significant correlation was found between the number of detached retinal quadrants and the fluorescence in that eye $(\mathrm{r}=.21, \mathrm{p}=.5520$, Table VI $)$.

No: significant correlation was found between the number of retinal breaks and the fluorescence in the detached eye $(r=.32$, $\mathrm{p}=.5100$, Table VI).

No significant correlation was found between the fluorescence in the fellow eye and the detached eye $(\mathrm{r}=.23, \mathrm{p}=.4882$, Table VI). We therefore failed to demonstrate any consensual change in $\mathrm{BAB}$ permeability.

\section{Discussion and Conclusions}

The eye is protected from the systemic circulation by the blood retinal barrier (BRB) 
Table II. Parameters of 11 patients with rhegmatogenous retinal detachment.

\begin{tabular}{rccccccccc}
\hline No & Sex & Age & Duration & Quads & No-Brks & PVR & Fellow & RD & Post-Op \\
\hline 1 & M & 73 & 2 & 3 & 2 & Y & 320 & 585 & 346 \\
2 & F & 40 & 12 & 2 & 1 & Y & 236 & 591 & 153 \\
3 & M & 20 & 2 & 1 & 1 & N & 250 & 357 & 134 \\
4 & F & 45 & 2 & 4 & 4 & N & 298 & 430 & 173 \\
5 & M & 51 & 1 & 3 & 2 & N & 286 & 502 & 203 \\
6 & F & 68 & 6 & 3 & 1 & N & 323 & 563 & 176 \\
7 & F & 61 & 1.50 & - & 1 & Y & 332 & 614 & 550 \\
8 & F & 45 & 80 & 3 & 1 & Y & 246 & 494 & 320 \\
9 & M & 65 & 2 & 3 & 5 & N & 311 & 548 & 356 \\
10 & M & 57 & 3 & 3 & 1 & N & 277 & 776 & 271 \\
11 & M & 69 & 2 & 1 & 1 & N & 292 & 536 & - \\
\hline
\end{tabular}

Key to Table II.

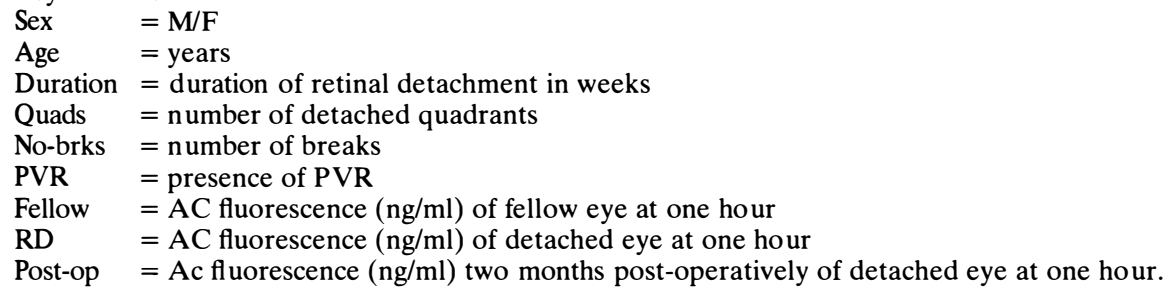

Table III. Basic statistical breakdown of parameters examined in 11 retinal detachment patients undergoing anterior segment fluorophotometry

\begin{tabular}{lccccc}
\hline & $N$ & Min & Max & Mean & Std Dev \\
\hline Age & 11 & 20 & 73 & 54 & 15.03 \\
Durn & 11 & 1 & 80 & 10.32 & 22.24 \\
Quads & 10 & 1 & 4 & 2.60 & 0.92 \\
No-brks & 11 & 1 & 5 & 288.3 & 1.34 \\
Fellow & 11 & 236.0 & 332.0 & 544.9 & 31.4 \\
RD & 11 & 357.0 & 776.0 & 268.2 & 102.3 \\
Post-op & 10 & 134.0 & 550.0 & & 122.0 \\
\hline
\end{tabular}

Key as for Table II.

Table IV. Data comparing anterior chamber fluorescence at 60 minutes following IV sodium fluorescein (14 mg/ $\mathrm{kg}$ ) in normal controls (group B) with that in test cases (group A). Test cases consisted of detached eyes preoperatively $(R D)$, two months post-operatively (post-op), and the fellow eye of the detached eye preoperatively (fellow).

\begin{tabular}{lcccccccc}
\hline & $\begin{array}{c}\text { 2-tailed } \\
t\end{array}$ & $\begin{array}{c}\text { Test } \\
p\end{array}$ & $\begin{array}{c}\text { group } \text { A } \\
\text { N1 }\end{array}$ & group B & $\begin{array}{c}\text { group A } \\
\text { Mean }\end{array}$ & $\begin{array}{c}\text { group B } \\
\text { Mean }\end{array}$ & $\begin{array}{c}\text { group A } \\
\text { Std Dev Dev }\end{array}$ & $\begin{array}{c}\text { group B } \\
\text { Std Dev Dev }\end{array}$ \\
\hline Fellow & -0.393 & 0.697 & 10 & 36 & 287.9 & 301.6 & 32.9 & 106.6 \\
RD & 6.262 & 0.000 & 10 & 36 & 546.0 & 301.6 & 107.3 & 106.6 \\
Post-op & -0.830 & 0.411 & 10 & 36 & 268.2 & 301.6 & 122.0 & 106.6 \\
\hline
\end{tabular}

and the blood aqueous barrier (BAB) which may be damaged by surgical trauma or ocular disease. The integrity of either barrier can be assessed by fluorophotometry.

Ideally vitreous fluorophotometry should be used to measure breakdown of the BRB caused by changes in the posterior segment of the eye and there is considerable experience of this in the diabetic eye. ${ }^{4}$ However, this technique relies upon clear ocular media and an intact vitreous gel, conditions which are never fulfilled in rhegmatogenous retinal detach- 
Table V. Data comparing anterior segment fluorescence between detached eyes with and without PVR.

\begin{tabular}{ccccccccc}
\hline & $\begin{array}{c}\text { 2-tailed } \\
t\end{array}$ & $\begin{array}{c}\text { Test } \\
p\end{array}$ & $\begin{array}{c}\text { group 1 } \\
\text { group 2 }\end{array}$ & $\begin{array}{c}\text { group 1 } \\
\text { Mean }\end{array}$ & $\begin{array}{c}\text { group 2 } \\
\text { Mean }\end{array}$ & $\begin{array}{c}\text { group 1 } \\
\text { Std Dev }\end{array}$ & $\begin{array}{c}\text { group 2 } \\
\text { Std Dev }\end{array}$ \\
\hline $\mathrm{RD}$ & 0.585 & 0.573 & 4 & 7 & 571.0 & 530.3 & 45.7 & 121.1 \\
\hline
\end{tabular}

Key to Table V.

group $1=$ detached eyes with PVR

group $2=$ detached eyes without PVR

$\mathrm{p}=0.573$ comparing groups $1 \& 2$.

ment. Opacities in the vitreous gel produce reflection artefacts which together with fluorescein pooling in the retrohyaloid space that occurs with posterior vitreous detachment, render scans uninterpretable. In contrast, anterior segment scans are free from these artefacts and are easily reproduced and interpreted.

Iris angiography, which has been previously used to monitor $\mathrm{BAB}$ recovery following surgery, gives only a qualitative assessment ${ }^{5}$ but anterior segment fluorophotometry enables quantification of the degree and duration of breakdown of the BAB. It is a simple, objective and reproducible technique, relatively free from artefacts, which measures fluorescence along the visual axis of the eye in the anterior chamber.

The fluorescence measured is derived from the contributions of the metabolites of intravenous fluorescein which are free fluorescein, fluorescein glucuronide and plasma bound fluorescein and fluorescein glucuronide. There are various ways of using the data from the fluorophotometer ${ }^{6-11}$ none of which are without problems. The derivation of formulae used to describe the diffusion and permeability characteristics of fluorescein in the eye involve some basic assumptions that may not be very accurate physiologically, but they give a close approximation.
It has been previously shown that anterior segment fluorophotometry can be used to quantify inflammation in acute anterior uveitis and is more precise and accurate for detecting changes in permeability than clinical observations of flare and cells. ${ }^{1}$

One might wonder how changes in anterior segment permeability may be caused by changes in the posterior segment. A possible explanation for this is that blood vessels in the iris and ciliary body are much more permeable than those in the retina. In rabbits, the blood vessels constituting the $\mathrm{BAB}$ were more permeable than those of the BRB by a factor of ten ${ }^{12,13}$ and similar results were found in man by van Best who correlated permeability of the BAB and BRB.${ }^{14}$ Being highly permeable, fluorescein acts as an excellent marker to detect increased permeability through the iris and ciliary body. Fluorescence levels in the AC represent permeability changes in the iris and ciliary body (presumably produced by an inflammatory response) rather than mere washout or overspill of fluorescence from the anterior vitreous gel.

Thus anterior segment fluorophotometry offers a relatively artefact-free, accurate and appropriate method for assessing changes in BAB permeability in the presence of a rhegmatogenous retinal detachment.

Our results demonstrate a significantly

Table VI. Correlation coefficients between parameters in 11 cases of rhegmatogenous retinal detachment.

\begin{tabular}{lrrrrrrr}
\hline & Age & Durn & Quads & No-brks & Fellow & RD & Post-op \\
\hline Age & 1.00 & -0.21 & 0.28 & 0.15 & 0.77 & 0.56 & 0.54 \\
Durn & -0.21 & 1.00 & 0.13 & -.23 & -.48 & -.13 & 0.09 \\
Quads & 0.28 & 0.13 & 1.00 & 0.52 & 0.42 & 0.21 & 0.39 \\
No-brks & 0.15 & -0.23 & 0.52 & 1.00 & 0.32 & -0.22 & 0.05 \\
Fellow & 0.77 & -0.40 & 0.42 & 0.32 & 1.00 & 0.23 & 0.54 \\
RD & 0.56 & -0.13 & 0.21 & -0.22 & 0.23 & 1.00 & 0.41 \\
Post-op & 0.54 & 0.09 & 0.39 & 0.05 & 0.54 & 0.41 & 1.00 \\
\hline
\end{tabular}

Key as for Table II. 
greater anterior segment fluorescence in phakic eyes with spontaneous first time rhegmatogenous retinal detachment than in normal controls. We have also shown that this fluorescence returns to normal levels within two months following successful surgery.

The increase in fluorescence is most likely to be due to an increase in $\mathrm{BAB}$ permeability, probably induced by local intraocular factors released from damaged retina or RPE. This is indirectly supported by clinical and experimental evidence. Tsuboi and co-workers ${ }^{15}$ found a significant increase in permeability across the RPE in detached eyes with retinal tears compared with fellow eyes used as controls. In addition, Cantrill and Pederson ${ }^{16}$ have demonstrated a two-fold increase in posteriorly directed flow of fluid from the vitreous in eyes of monkeys with detached retinas compared with the fellow eye controls. These permeability changes must be induced by some local effect which could be partly mechanical (fluid passing through the retinal break, physical disruption of tissues caused by the separation of the neurosensory retina and RPE) but probably also includes the release of factors that can influence local vascular permeability, thereby inducing the effects that we have observed in the anterior segment.

These anterior segment permeability changes appear to be transient since there is no significant difference between the control group and the re-attached eyes two months post-operatively. These changes are also restricted to the affected eye and not the fellow eye as we found no significant difference between anterior segment fluorescence in the fellow eyes and the control group or between the fellow eye and the detached eye.

The mean anterior segment fluorescence of eyes with PVR $(571 \mathrm{ng} / \mathrm{ml})$ was greater than that of eyes without PVR $(530 \mathrm{ng} / \mathrm{ml})$ but this difference was not statistically significant in our sample which would need to be larger for proof of significance.

The amount of anterior segment fluorescence was not related to either the duration or extent of the retinal detachment or to the number of retinal breaks.

We did find a significant positive correlation between the age of the patient and the fluorescence in the fellow eye which, since the fellow eye group did not differ significantly from the control group, implies an age-related increase in AC fluorescence which has been previously demonstrated. ${ }^{1}$ This does not, however, result from an increase in $\mathrm{BAB}$ permeability but is a consequence of the increase in plasma fluorescence which has been shown to be age-related. ${ }^{15}$

This study has used anterior segment fluorophotometry to demonstrate a previously unreported significant increase in permeability of the blood aqueous barrier in phakic eyes with rhegmatogenous retinal detachment. This may well be a significant factor in the development of complications such as PVR or rubeosis but further studies are needed to establish this.

Key words: anterior segment fluorophotometry, blood-aqueous barrier, rhegmatogenous retinal detachment.

\section{References}

${ }^{1}$ Fearnley IR, Spalton DJ, Smith SE: Anterior segment fluorophotometry in acute anterior uveitis. Arch Ophthalmol 1987, 105: 649-56.

${ }^{2}$ Myake K, Asakura M, Maekubo K: Consensual reactions of human blood-aqueous barrier to implant operations. Arch Ophthalmol 1984, 102: 558-61.

${ }^{3}$ Zeimer RC, Blair NP, Cunha-Vas JG: Vitreous fluorophotometry for clinical research: $I$. Description and evaluation of a new fluorophotometer. Arch Ophthalmol 1983, 101: 1753-6.

${ }^{4}$ Cunha-Vas JG, de Abreu JRF, Campos AJ, Figo JM: Early breakdown of the blood-retinal barrier in diabetes. Br J Ophthalmol 1975, 59: 649-56.

${ }^{5}$ Easty D, Dallas N, O'Malley R: Aphakic macular oedema following prosthetic lens implantation. Br J Ophthalmol 1977, 61: 321-6.

${ }^{6}$ Myake K, Asakura M, Kobayashi H: Effect of intraocular lens fixation on the blood-aqueous barrier. Am J Ophthalmol 1984, 98: 451-5.

${ }^{7}$ Sanders DR, Kraff MC, Lieberman HL, Peyman GA, Tarabishy S: Breakdown and re-establishment of blood-aqueous barrier with implant surgery: Arch Ophthalmol 1982, 100: 588-90.

${ }^{8}$ Liesegang TJ, Bourne WM, Brubaker RF: The effect of cataract surgery on the blood-aqueous barrier. Ophthalmology 1984, 91: 399-402.

${ }^{9}$ Sawa M, Sakanishi Y, Okuno Y, Shimizu H: Posterior chamber lens implantation and anterior segment barrier function: a fluorophotometric study. Jpn J Ophthalmol 1988, 32: 297-303.

${ }^{10}$ Araie M, Sawa M, Takase M: Effect of topical indomethacin on the blood-aqueous barrier after intracapsular extraction of senile cataract: a fluorophotometric study. Jpn J Ophthalmol 1981, 25: $237-47$. 
${ }^{11}$ Menerath JM, Coulangeon LM, Al-Odeh A: Evaluation fluorophotometrique des barrieres hematoculaires dans la chirurgie de la cataract. Ophthalmologie 1988, 2: 37-40.

${ }^{12}$ Rapoport SI: Blood-brain barrier in Physiology and Medicine New York: Raven Press, 1976.

${ }^{13}$ Novack GD and Leopold IH: The blood-aqueous and blood-brain barriers to permeability. Am J Ophthalmol 1988, 105: 412-6.
${ }^{14}$ van Best JA, Kappelhof JP, Laterveer L, Oosterhuis JA: Blood aqueous barrier permeability vs age by fluorophotometry. Curr Eye Res 1987, 6: 855-63.

${ }^{15}$ Tsuboi S, Taki-Noie J, Emi K, Manabe R: Fluid dynamics in eyes with rhegmatogenous retinal detachments. Am J Ophthalmol 1985, 99: 673-6.

${ }^{16}$ Cantrill HL and Pederson JE: Experimental retinal detachment. III. Vitreous fluorophotometry. Arch Ophthalmol 1982, 100: 1810-13. 